\title{
Sistem Pendukung Keputusan Penerima Bantuan Pangan Non Tunai Dengan Metode Hybrid AHP- SAW
}

\author{
Satria Rizki Arianto ${ }^{1}$, Sri Siswanti ${ }^{2^{*}}$,Wawan Laksito Yuly Saptomo ${ }^{3}$ \\ ${ }^{1}$ Sistem Informasi/STMIK Sinar Nusantara \\ JI. KH. Samanhudi 84-86 Surakarta, 0271-716500, e-mail: Solo.orsol@gmail.com \\ $2^{*}$ Teknik Informatika/ STMIK Sinar Nusantara \\ Jl. KH. Samanhudi 84-86 Surakarta, 0271-716500, e-mail: syswanty@sinus.ac.id \\ ${ }^{3}$ Teknik Informatika/ STMIK Sinar Nusantara \\ Jl. KH. Samanhudi 84-86 Surakarta, 0271-716500, e-mail: syswanty@sinus.ac.id
}

\section{ARTICLE INFO}

Article history:

Received 27 November 2019

Received in revised form 02 January 2020

Accepted 20 January 2020

Available online 31 January 2020
Non-Cash Food Aid is a monthly social aid program from government for beneficiary families by electronic account mechanism. This electronic account later has function for this family to buy food materials in grocery stores or e-stores which cooperate with bank. The village heads make proposal about the poor family in their area as beneficiary family for this Non-Cash Food Aid after having observation. However, there is problem for deciding and filtering the data of citizens whether they deserve or not to accept this social aid. Somehow, few of middle class people are included in the data of the poor as beneficiary family. In this case, there is no method to decide the beneficiary of Non-Cash Food Aid. Therefore, the aim of this research is the methods application of Analytical Hierarchy Process (AHP) and Simple Additive Weighting (SAW). Based on the research result, there is decision support system for Non-Cash Food Aid data by using AHP and SAW method. Based on test result of old and new ranking system with 10 data sampling, there are 9 different data in this ranking system. It happened because the old system calculation only used 1 criterion, monthly income. Meanwhile, new ranking system used all criterions having value and quality

Keywords: Decision support system, Analytical Hierarchy Process, Simple Additive Weighting

\section{ABSTRACT}

\section{Introduction}

Bantuan Pangan Non Tunai adalah program pemerintah tentang bantuan pangan yang diberikan kepada Keluarga Penerima Manfaat (KPM) setiap bulannya melalui mekanisme akun elektronik yang digunakan hanya untuk membeli pangan di e-Warong KUBE PKH / pedagang bahan pangan yang bekerjasama dengan Bank HIMBARA. Bertujuan untuk mengurangi beban Received November 27, 2019; Revised January 02, 2020; Accepted January 20, 2020 
pengeluaran serta memberikan nutrisi yang lebih seimbang kepada KPM secara tepat sasaran dan tepat waktu. [1]

Studi kasus penelitian di Desa Makamhaji Sukoharjo. Sistem Bantuan Pangan Non Tunai (BPNT) yang berjalan saat ini masih banyak kendala, seperti Data warga yang diusulkan oleh RT, RW / Kepala Desa langsung masuk ke data Warga Miskin dan penerima BPNT belum merata, karena banyak warga yang cukup mampu masuk dalam Data Warga penerima BPNT. Berdasarkan kendala tersebut menyebabkan beberapa data warga miskin di Desa Makamhaji kurang Valid dengan kriteria yang ada.

Indonesia menjadi negara pengkonsumsi beras terbesar di dunia, 95\% dari jumlah penduduknya mengkonsumsi beras sebagai pangan utama, dengan rata-rata konsumsi beras sebesar $113,7 \mathrm{~kg} / \mathrm{jiwa} /$ tahun. Tingkat konsumsi tersebut jauh di atas rata-rata konsumsi dunia yang hanya sebesar $60 \mathrm{~kg} / \mathrm{kapita} /$ tahun.

Kepala Desa Makamhaji memiliki tugas yang cukup berat yaitu harus mendata warga miskin untuk diajukan kepusat agar mendapatkan rekomendasi sebagai penerima BPNT. Sedangkan data jumlah KK di Desa Makamhaji Per Januari 2018 adalah 5219 KK. Padahal tidak seluruh warga masyarakat yang berhak mendapatkan BPNT, akan tetapi hanya khusus bagi warga miskin saja yang berhak untuk mendapatkan Bantuan Pangan Non Tunai.

Berdasarkan latar belakang permasalahan tersebut, diperlukan sebuah Sistem Pendukung Keputusan Penerima Bantuan Pangan Non Tunai dengan metode Hybrid AHP - SAW.

Sistem pengambilan keputusan pemilihan supplier dengan metode AHP (Analytical Hierarchy Process) untuk menentukan bobot dan metode SAW (Simple Additive Weighting) untuk menentukan rangking dari setiap alternatif, hasilnya adalah sistem ini dapat membantu penilaian secara pasti terhadap supplier dan dapat memudahkan evaluasi terhadap supplier.[2]

Penelitian [3] mengenai penentuan keluarga miskin dengan menggunakan AHP. Variabel yang diteliti adalah tanah, lantai, dinding, MCK, penerangan, air minum, makan, daging, bbm, pakaian, berobat, penghasilan, pendidikan dan asset. Hasil pengujian memperoleh keakuratan sebesar $92,86 \%$ dari 70 data sampel lapangan. AHP juga digunakan untuk penilaian kinerja [4] [5][6][7]

Penelitian [8] tentang metode Simple Additive Weighting (SAW) yang dapat mempercepat proses menentukan pemberian raskin dengan perhitungan yang akurat. Hasil penelitian dari metode Simple Additive Weighting (SAW) yang telah diperhitungkan dapat disimpulkan bahwa pemberian Raskin diberikan kepada Sukriyah dengan hasil 2.75. Penelitian [9][10][11][12] juga meneliti tentang penentuan penerimaan beras bagi keluarga keluarga miskin (Raskin).

Perbedaan dengan peneliti sebelumnya adalah penggunaan metode Hybrid AHP dan $S A W$, sedang peneliti lain hanya menggunakan metode AHP saja atau SAW saja, ada peneliti yang menggunakan Metode AHP-SAW namun untuk kasus yang berbeda.

\section{Research Method}

\subsection{Metode AHP (Analytical Hierarchy Process)}

Metode Analytical Hierarchy Process (AHP) dikembangkan oleh Prof. Thomas Lorie Saaty dari Wharston Business school untuk mencari ranking atau urutan prioritas dari berbagai alternatif dalam pemecahan suatu permasalahan. Metode AHP (Analytical Hierarchy Process) merupakan salah satu metode Multi Criteria Decision Making (MCDM) yang sangat baik dalam memodelkan pendapat para ahli dalam sistem pendukung keputusan. [13]

Langkah - langkah AHP :

a. Perbandingan Prioritas

Perbandingan prioritas menggunakan perbandingan berpasangan yang dipresentasikan dalam bentuk matriks. Skala untuk mengisi matrik menggunakan skala Saaty denagn penejlasan seperti pada Tabel 1 . 
Tabel 1. Tabel perbandingan Saaty

\begin{tabular}{|c|l|}
\hline $\begin{array}{c}\text { Intensitas } \\
\text { kepentingan }\end{array}$ & \multicolumn{1}{c|}{ Definisi } \\
\hline 1 & Sama Penting (Equal) \\
\hline 3 & Cukup Penting (Moderate) \\
\hline 5 & Lebih Penting (Strong) \\
\hline 7 & Sangat Lebih Penting (Very) \\
\hline 9 & Multlak Lebih Penting (Extreme) \\
\hline
\end{tabular}

b. Normalisasi AHP

Nilai kolom kriteria $\Sigma$ Kolom

c. Eigen Vektor

$$
\lambda=\frac{\Sigma \text { Baris }}{\text { kolom }}
$$

d. Eigen Maksimum

$$
\lambda_{\max }=\left(\lambda_{1} x \sum \text { Baris }_{1}\right)+\left(\lambda_{2} x \sum \text { Baris }_{2}\right)+\ldots \ldots+\left(\lambda_{n} x \sum \text { Baris }_{n}\right.
$$

e. Indeks Konsistensi

$$
C I=\frac{\lambda_{\operatorname{Max}}-n}{n-1}
$$

f. Rasio Konsistensi

$$
C R=\frac{C I}{R I}
$$

\subsection{SAW (Simple Additive Weighting)}

Metode SAW banyak dikenal sebagai metode penjumlahan terbobot. Konsep metode SAW adalah mencari penjumlahan terbobot dari rating kinerja pada setiap alternatif pada semua atribut. [14], [9].

Langkah - langkah SAW :

a. Menentukan Bobot Kriteria

Bobot Kriterianya adalah Eigen Vektor dari Hasil Hitung AHP.

b. Menentukan Nilai Kriteria

c. Normalisasi

$$
r_{i j}=\left\{\begin{array}{l}
\frac{X_{i j}}{\max _{x i j}}, \text { Jika } \mathrm{j} \text { adalah atribut keuntungan (benefit) } \\
\frac{\min _{x i j}}{X_{i j}}, \quad \text { Jika } \mathrm{j} \text { adalah atribut biaya (cost) }
\end{array}\right.
$$

d. Pencarian Keputusan

$$
v_{i}=\sum_{i=1}^{n} W_{j} * r_{i j}
$$

e. Perangkingan

TRANSFORMATIKA Vol. 17, No. 2, January 2020 : 200 - 208 


\section{Results and Analysis}

\subsection{Perhitungan AHP}

Data awal pada penelitian ini dapat di lihat pada Tabel 2.

Tabel 2. Data Awal

\begin{tabular}{|c|c|c|c|c|c|l|l|c|}
\hline Kode & C1 & C2 & C3 & C4 & C5 & C6 & \multicolumn{1}{c|}{ C7 } & C8 \\
\hline A1 & 1.100 .000 & 2 & Tidak tetap & Milik Sendiri & Tegel & Punya & Punya & SMP \\
\hline A2 & 2.100 .000 & 2 & Tetap & Milik Sendiri & Keramik & Punya & Punya & D1 \\
\hline A3 & 800.000 & 3 & Tidak tetap & Sewa & Tanah & Tidak Punya & Tidak Punya & $\begin{array}{c}\text { Tidak } \\
\text { Sekolah }\end{array}$ \\
\hline A4 & 1.600 .000 & 5 & Tetap & Milik Sendiri & Keramik & Punya & Tidak Punya & SMA \\
\hline A5 & 1.400 .000 & 3 & Tidak tetap & Sewa & Tegel & Tidak Punya & Tidak Punya & SD \\
\hline A6 & 1.000 .000 & 3 & Tidak tetap & Sewa & Tegel & Punya & Tidak Punya & SD \\
\hline A7 & 750.000 & 3 & Tidak tetap & Sewa & Tegel & Tidak Punya & Tidak Punya & $\begin{array}{c}\text { Tidak } \\
\text { Sekolah }\end{array}$ \\
\hline A8 & 1.200 .000 & 2 & Tetap & Milik Sendiri & Keramik & Punya & Punya & SMP \\
\hline A9 & 1.400 .000 & 2 & Tetap & Milik Sendiri & Keramik & Punya & Punya & SMP \\
\hline A10 & 1.800 .000 & 5 & Tetap & Sewa & Keramik & Punya & Tidak Punya & S1 \\
\hline
\end{tabular}

Keterangan :

C1 (Pendapatan Per Bulan), C2 (Tanggungan Keluarga), C3 (Pekerjaan), C4 (Kepemilikan Rumah), C5 (Lantai Rumah), C6 (Kepemilikan MCK), C7 (Kepemilikan Lahan), C8 (Pendidikan KK).

Selanjutnya menentukan perbandingan berpasangan tiap kriteria dengan dasar tabel perbandingan saaty pada Tabel 1 . Hasil perbandingan prioritas dapat di lihat pada Tabel 3 .

Tabel 3. Perbandingan Prioritas

\begin{tabular}{|c|c|c|c|c|c|c|c|c|}
\hline & $\begin{array}{c}\text { Pendapatan } \\
\text { /bln }\end{array}$ & $\begin{array}{c}\text { Jumlah } \\
\text { Tanggungan }\end{array}$ & Pekerjaan & $\begin{array}{c}\text { Kepemilikan } \\
\text { Rumah }\end{array}$ & $\begin{array}{l}\text { Lantai } \\
\text { Rumah }\end{array}$ & MCK & $\begin{array}{c}\text { Kepemilikan } \\
\text { Lahan }\end{array}$ & $\begin{array}{c}\text { Pendidikan } \\
\text { KK }\end{array}$ \\
\hline $\begin{array}{l}\text { Pendapatan } \\
\text { /bln }\end{array}$ & 1,00 & 3,00 & 3,00 & 5,00 & 5,00 & 5,00 & 7,00 & 7,00 \\
\hline $\begin{array}{l}\text { Jumlah } \\
\text { Tanggungan } \\
\end{array}$ & 0,33 & 1,00 & 1,00 & 3,00 & 3,00 & 3,00 & 5,00 & 5,00 \\
\hline Pekerjaan & 0,33 & 1,00 & 1,00 & 3,00 & 3,00 & 3,00 & 5,00 & 5,00 \\
\hline $\begin{array}{l}\text { Kepemilikan } \\
\text { Rumah }\end{array}$ & 0,20 & 0,33 & 0,33 & 1,00 & 1,00 & 1,00 & 3,00 & 3,00 \\
\hline $\begin{array}{l}\text { Lantai } \\
\text { Rumah }\end{array}$ & 0,20 & 0,33 & 0,33 & 1,00 & 1,00 & 1 & 1 & 1 \\
\hline MCK & 0,20 & 0,33 & 0,33 & 1,00 & 1,00 & 1 & 1 & 1 \\
\hline $\begin{array}{l}\text { Kepemilikan } \\
\text { Lahan }\end{array}$ & 0,14 & 0,20 & 0,20 & 0,33 & 1,00 & 1,00 & 1 & 1 \\
\hline $\begin{array}{l}\text { Pendidikan } \\
\text { KK }\end{array}$ & 0,14 & 0,20 & 0,20 & 0,33 & 1,00 & 1,00 & 1,00 & 1 \\
\hline $\begin{array}{l}\text { Jumlah } \\
\text { Kolom }\end{array}$ & 2,55 & 6,40 & 6,40 & 14,67 & 16,00 & 16,00 & 24,00 & 24,00 \\
\hline
\end{tabular}

Langkah selanjutnya setelah penentuan perbandingan prioritas dilakukan normalisasi tiap kriteria berdasarkan persamaan (2) dapat dilihat pada Tabel 4. 
Tabel 4. Normalisasi Tiap Kriteria

\begin{tabular}{|c|c|c|c|c|c|c|c|c|c|}
\hline & $\begin{array}{l}\text { Pendapatan } \\
\text { /bln }\end{array}$ & $\begin{array}{c}\text { Jumlah } \\
\text { Tanggungan }\end{array}$ & Pekerjaan & $\begin{array}{c}\text { Kepemilikan } \\
\text { Rumah }\end{array}$ & $\begin{array}{l}\text { Lantai } \\
\text { Rumah }\end{array}$ & MCK & $\begin{array}{c}\text { Kepemilikan } \\
\text { Lahan }\end{array}$ & $\begin{array}{c}\text { Pendidikan } \\
\text { KK }\end{array}$ & $\begin{array}{c}\text { Jumlah } \\
\text { Baris / } \\
\text { Bobot }\end{array}$ \\
\hline $\begin{array}{l}\text { Pendapatan } \\
\text { /bln }\end{array}$ & 0,39 & 0,47 & 0,47 & 0,34 & 0,31 & 0,3125 & 0,291666667 & 0,291666667 & 2,88 \\
\hline $\begin{array}{l}\text { Jumlah } \\
\text { Tanggungan }\end{array}$ & 0,13 & 0,16 & 0,16 & 0,20 & 0,19 & 0,1875 & 0,208333333 & 0,208333333 & 1,44 \\
\hline Pekerjaan & 0,13 & 0,16 & 0,16 & 0,20 & 0,19 & 0,1875 & 0,208333333 & 0,208333333 & 1,44 \\
\hline $\begin{array}{l}\text { Kepemilikan } \\
\text { Rumah }\end{array}$ & 0,08 & 0,05 & 0,05 & 0,07 & 0,06 & 0,0625 & 0,125 & 0,125 & 0,63 \\
\hline $\begin{array}{l}\text { Lantai } \\
\text { Rumah }\end{array}$ & 0,08 & 0,05 & 0,05 & 0,07 & 0,06 & 0,0625 & 0,041666667 & 0,041666667 & 0,46 \\
\hline MCK & 0,08 & 0,05 & 0,05 & 0,07 & 0,06 & 0,0625 & 0,041666667 & 0,041666667 & 0,46 \\
\hline $\begin{array}{l}\text { Kepemilikan } \\
\text { Lahan }\end{array}$ & 0,06 & 0,03 & 0,03 & 0,02 & 0,06 & 0,0625 & 0,041666667 & 0,041666667 & 0,35 \\
\hline $\begin{array}{l}\text { Pendidikan } \\
\text { KK }\end{array}$ & 0,06 & 0,03 & 0,03 & 0,02 & 0,06 & 0,0625 & 0,041666667 & 0,041666667 & 0,35 \\
\hline Jumlah & 1,00 & 1,00 & 1,00 & 1,00 & 1,00 & 1,00 & 1,00 & 1,00 & \\
\hline
\end{tabular}

Normalisasi tiap kriteria selanjutnya sudah ditentukan, langkah selanjutnya adalah menghitung nilai eigen vektor berdasarkan persamaan (3) dapat dilihat pada Tabel 5.

Tabel 5. Eigen Vektor

\begin{tabular}{|l|c|}
\hline \multicolumn{2}{|c|}{ Menghitung Nilai eigen Vektor } \\
\hline Rumus & Jumlah Baris/Kolom \\
\hline Eigen Vektor Pendapatan /bln & 0,36 \\
\hline Eigen Vektor Jumlah Tanggungan & 0,18 \\
\hline Eigen Vektor Pekerjaan & 0,18 \\
\hline Eigen Vektor Kepemilikan Rumah & 0,08 \\
\hline Eigen Vektor Lantai Rumah & 0,06 \\
\hline Eigen Vektor MCK & 0,06 \\
\hline Eigen Vektor Kepemilikan Lahan & 0,04 \\
\hline Eigen Vektor Pendidikan KK & 0,04 \\
\hline
\end{tabular}

Berdasarkan Tabel 5, maka Eigen Maksimum berdasarkan persamaan (4), adalah sebesar 8,301757447. Pencarian Indeks Konsistensi berdasarkan eigen maksimum dilakukan berdasarkan persamaan (5), dimana hasil indeks konsistensi (CI) adalah 0,043108207 .

Langkah selanjutnya dilakukan penghitungan Rasio Konsistensi (CR) berdasarkan persamaan (6) dengan nilai $\mathbf{0 , 0 2 9 0}$ atau dinyatakan konsisten.

TRANSFORMATIKA Vol. 17, No. 2, January 2020 : $200-208$ 


\subsection{Perhitungan SAW}

Nilai Eigen Vektor pada Tabel 5 dapat digunakan sebagai Rata-rata bobot tiap kriteria.

Setelah di tentukan rata-rata bobot tiap kriteria diatas, selanjutnya Menentukan nilai tiap kriteria. Dapat dilihat pada Tabel 6.

Tabel 6. Nilai Tiap Kriteria

\begin{tabular}{|c|c|c|}
\hline No & Kriteria & Nilai \\
\hline \multirow{5}{*}{1} & \multicolumn{2}{|c|}{ Pendapatan Per Bulan } \\
\hline & $<1000000$ & 4 \\
\hline & $1.000 .000-1.500 .000$ & 3 \\
\hline & $1.500 .000-2.000 .000$ & 2 \\
\hline & $>2.000 .000$ & 1 \\
\hline \multirow{6}{*}{2} & \multicolumn{2}{|c|}{$\begin{array}{l}\text { Jumlah Tanggungan keluarga } \\
\end{array}$} \\
\hline & $>=4$ Anak & 5 \\
\hline & 3 Anak & 4 \\
\hline & 2 Anak & 3 \\
\hline & 1 Anak & 2 \\
\hline & Tidak Punya & 1 \\
\hline \multirow{3}{*}{3} & \multicolumn{2}{|c|}{ Jenis Pekerjaan } \\
\hline & Tidak Tetap & 5 \\
\hline & Tetap & 1 \\
\hline \multirow{4}{*}{4} & \multicolumn{2}{|c|}{ Kepemilikan Rumah Tinggal } \\
\hline & Numpang & 5 \\
\hline & Sewa & 3 \\
\hline & Milik Sendiri & 1 \\
\hline \multirow{4}{*}{5} & Lantai Rumah & \\
\hline & Tanah & 5 \\
\hline & Tegel & 3 \\
\hline & Keramik & 1 \\
\hline \multirow{3}{*}{6} & \multicolumn{2}{|c|}{ MCK (Kamar Mandi) } \\
\hline & Tidak Punya & 5 \\
\hline & Punya & 1 \\
\hline \multirow{3}{*}{7} & \multicolumn{2}{|c|}{ Kepemilikan Lahan } \\
\hline & Tidak Punya & 5 \\
\hline & Punya & 1 \\
\hline \multirow{6}{*}{8.} & \multicolumn{2}{|c|}{ Pendidikan Kepala Keluarga } \\
\hline & Tidak Sekolah & 5 \\
\hline & SD & 4 \\
\hline & SMP & 3 \\
\hline & SMA & 2 \\
\hline & $>=\mathrm{D} 1$ & 1 \\
\hline
\end{tabular}

Penentukan nilai di tiap kriterianya berdasar data awal pada Tabel 2. Setelah di konversi kedalam bentuk nilai, maka akan seperti pada Tabel 7. 
Tabel 7. Menentukan Nilai Tiap Kriteria

\begin{tabular}{|l|c|c|c|c|c|c|c|c|}
\hline kode & C1 & C2 & C3 & C4 & C5 & C6 & C7 & C8 \\
\hline A1 & 3 & 3 & 5 & 1 & 3 & 1 & 1 & 3 \\
\hline A2 & 1 & 3 & 1 & 1 & 1 & 1 & 1 & 1 \\
\hline A3 & 4 & 4 & 5 & 3 & 5 & 5 & 5 & 5 \\
\hline A4 & 2 & 5 & 1 & 1 & 1 & 1 & 5 & 2 \\
\hline A5 & 3 & 4 & 5 & 3 & 3 & 5 & 5 & 4 \\
\hline
\end{tabular}

Setelah dilakukan penentuan nilai tiap kriteria Selanjutnya melakukan proses normalisasi dari tabel 10 berdasarkan persamaan (6) . Hasilnya seperti Tabel 8.

Tabel 8. Normalsasi

\begin{tabular}{|l|r|r|r|r|r|r|r|r|}
\hline kode & \multicolumn{1}{l|}{ C1 } & \multicolumn{1}{l|}{ C3 } & \multicolumn{1}{l|}{ C4 } & C5 & C6 & C7 & C8 \\
\hline A1 & 0,75 & 0,6 & 1 & 0,33 & 0,6 & 0,2 & 0,2 & 0,6 \\
\hline A2 & 0,25 & 0,6 & 0,2 & 0,33 & 0,2 & 0,2 & 0,2 & 0,2 \\
\hline A3 & 1 & 0,8 & 1 & 1 & 1 & 1 & 1 & 1 \\
\hline A4 & 0,5 & 1 & 0,2 & 0,33 & 0,2 & 0,2 & 1 & 0,4 \\
\hline A5 & 0,75 & 0,8 & 1 & 1 & 0,6 & 1 & 1 & 0,8 \\
\hline A6 & 0,75 & 0,8 & 1 & 1 & 0,6 & 0,2 & 1 & 0,8 \\
\hline A7 & 1 & 0,8 & 1 & 1 & 0,6 & 1 & 1 & 1 \\
\hline A8 & 0,75 & 0,6 & 0,2 & 0,33 & 0,2 & 0,2 & 0,2 & 0,6 \\
\hline A9 & 0,75 & 0,6 & 0,2 & 0,33 & 0,2 & 0,2 & 0,2 & 0,6 \\
\hline A10 & 0,5 & 1 & 0,2 & 1 & 0,2 & 0,2 & 1 & 0,2 \\
\hline
\end{tabular}

Hasil Pencarian Keputusan berdasarkan persamaan (7) seperti Tabel 9.

Tabel 9. Pencarian Keputusan

\begin{tabular}{|l|r|r|}
\hline Kode & Hasil & Rangking \\
\hline a1 & 0,66465253 & 5 \\
\hline a2 & 0,300384736 & 10 \\
\hline a3 & 0,964017272 & 1 \\
\hline a4 & 0,505995708 & 7 \\
\hline a5 & 0,84237283 & 3 \\
\hline a6 & 0,796468828 & 4 \\
\hline a7 & 0,94106527 & 2 \\
\hline a8 & 0,497769615 & 8 \\
\hline a9 & 0,497769615 & 9 \\
\hline a10 & 0,549399664 & 6 \\
\hline
\end{tabular}

\subsection{Hasil Perankingan sistem Lama dengan Sistem Baru}

Perangkingan dengan sistem lama dilakukan dengan cara mengurutkan data berdasarkan kriteria pendapatan dari nilai terkecil ke terbesar, kemudian hasil diambil dan ditetapkan sebagai warga miskin penerima BPNT sesuai kuota. Perhitungan menggunakan sistem baru menggunakan semua kriteria yang ada yaitu pendapatan per bulan, jumlah tanggungan

TRANSFORMATIKA Vol. 17, No. 2, January 2020 : $200-208$ 
keluarga, jenis pekerjaan, kepemilikan rumah tinggal, MCK, kepemilikan lahan, dan pendidikan kepala keluarga serta perhitungannya menggunakan metode AHP dan SAW. Hasil pengujian validitas seperti pada Tabel 10.

Tabel 10. Hasil Perangkingan Sistem Lama dengan Sistem Baru

\begin{tabular}{|c|r|r|c|c|c|}
\hline \multirow{2}{*}{ Kode } & \multicolumn{2}{|c|}{ Sistem lama } & \multicolumn{2}{|c|}{ Sistem baru } & \multirow{2}{*}{ Kesimpulan } \\
\cline { 2 - 6 } & Pendapatan & Rangking & Hasil & rank & \\
\hline A1 & 1.100 .000 & 4 & 0,66465253 & 5 & Tidak Sama \\
\hline A2 & 2.100 .000 & 10 & 0,300384736 & 10 & Sama \\
\hline A3 & 800.000 & 2 & 0,964017272 & 1 & Tidak Sama \\
\hline A4 & 1.600 .000 & 8 & 0,505995708 & 7 & Tidak Sama \\
\hline A5 & 1.400 .000 & 6 & 0,84237283 & 3 & Tidak Sama \\
\hline A6 & 1.000 .000 & 3 & 0,796468828 & 4 & Tidak Sama \\
\hline A7 & 750.000 & 1 & 0,94106527 & 2 & Tidak Sama \\
\hline A8 & 1.200 .000 & 5 & 0,497769615 & 8 & Tidak Sama \\
\hline A9 & 1.400 .000 & 7 & 0,497769615 & 9 & Tidak Sama \\
\hline A10 & 1.800 .000 & 9 & 0,549399664 & 6 & Tidak Sama \\
\hline
\end{tabular}

Terdapat perbedaan pada calon penerima BPNT sistem lama dengan sistem baru, pada sistem lama urutannya adalah A7, A3, A6, A1, A8, A5, A9, A4, A10, dan A2, sedangkan pada sistem baru urutannya adalah A3, A7, A5, A6, A1, A10, A4, A8, A9 dan A2. Hasil tersebut dapat terjadi karena pada perhitungan sistem lama hanya menggunakan satu kriteria yaitu pendapatan per bulan, sedangkan pada perhitungan sistem baru menggunakan semua kriteria yang ada, dimana masing-masing kriteria memiliki nilai dan bobot.

Pada sistem baru tidak menentukan berhak atau tidak berhak calon penerima, dikarenakan aturan yang berjalan berdasarkan jumlah kuota bukan berdasarkan Passing Grade.

\section{Conclusion}

Kesimpulan yang dapat diambil dari hasil analisis, perancangan dan pembuatan Sistem Pendukung Keputusan Penerima Bantuan Pangan Non Tunai di Desa Makamhaji menggunakan Metode Hybrid AHP - SAW adalah Tercapainya tujuan untuk merancang, membangun, dan mengimplementasikan sistem pendukung keputusan penerimaan bantuan pangan non tunai yang dapat menerapkan semua kriteria yang ada dengan metode Hybrid AHP - SAW.

Pada penelitian ini penulis berhasil menerapkan metode AHP untuk menentukan bobot kriteria dan menerapkan metode SAW untuk perangkingan alternatif pada penerima BPNT. Mengimplementasikan fitur - fitur seperti Input data pengguna, Input data penduduk, Input data kriteria tiap-tiap penduduk, perbandingan tiap bobot, serta menghasilkan output berupa data penduduk penerima BPNT.

\section{References}

[1] P. Maharani, "Pedoman Umum Bantuan Pangan Non Tunai," pp. 1-136, 2017.

[2] A. Pradipta and A. Diana, "Sistem Penunjang Keputusan Pemilihan Supplier pada Apotek dengan Metode AHP dan SAW ( Studi Kasus Apotek XYZ )," Semin. Nas. SISFOTEK (Sistem Inf. dan Teknol. informasi), vol. 3584, pp. 107-114, 2017.

[3] Z. Atmaja, M. Hasbi, and T. Susyanto, "Sistem Pendukung Keputusan Penentu Keluarga Miskin Metode Ahp Berbasis Web Dinamis Study Kasus Kelurahan Ketaon, Banyudono, Boyolal," TIKomSiN, vol. 3, no. 1, pp. 11-19, 2017.

[4] E. Ruskan, "Kolaborasi Metode Saw Dan Ahp Untuk Sistem Pendukung Keputusan 
Penilaian Kinerja Asisten Laboratorium," J. Sist. Inf., vol. 9, no. 1, pp. 1204-1215, 2017.

[5] S. Rakasiwi, "Sistem Pendukung Keputusan Dalam Menentukan Penilaian Kinerja Guru Dengan Metode Analytical Hierarchy Process (Ahp)," Simetris J. Tek. Mesin, Elektro dan Ilmu Komput., vol. 9, no. 2, pp. 1001-1008, 2018.

[6] M. Hardianti et al., "Pegawai Menggunakan Metode Analytical Hierarchy Process ( Ahp )," vol. 9, no. 2, pp. 70-77, 2017.

[7] M. Hismawati, "Pengambilan Keputusan Dalam Penerima Bantuan Raskin Dengan Metode Simple Additive Weigthing ( SAW )," J. Swabumi, vol. 6, no. 2, pp. 110-116, 2018.

[8] Jamal Abdul Nasir, "Sistem Pendukung Keputusan Pemberian Beras Untuk Keluarga Miskin Dengan Metode Simple Additive Weighting," Paradigma, vol. 19, no. 2, pp. 108$112,2017$.

[9] G. Y. K. S. Siregar Pahu, L. R. Putri, N. Nungsiyati, and R. Renaldo, "Sistem Pendukung Keputusan Menentukan Calon Penerima Raskin Menggunakan Metode Simple Additive Weighting," J. Teknoinfo, vol. 12, no. 2, p. 82, 2018.

[10] T. P. Handayani, "Analisa Penentuan Perubahan Calon Penerima Rastra (Beras Sejahtera) Dengan Metode Simple Additive Method (Saw) Di Desa Huidu Kabupaten Gorontalo," InfoTekJar (Jurnal Nas. Inform. dan Teknol. Jaringan), vol. 2, no. 1, pp. 22-26, 2017.

[11] F. Sofyan, E. Nurfarida, E. Febry, and W. Yustika, "Sistem Pendukung Keputusan Penerimaan Raskin Desa Mabung Kabupaten Nganjuk Menerapkan Metode Simple Additive Weighting," J. Inform. Multimed., vol. 08, no. 02, pp. 17-23, 2016.

[12] A. S. Rini and D. Soyusiawaty, "Sistem Pendukung Keputusan Seleksi Penerimaan Beras Untuk Keluarga Miskin Dengan Metode Simple Additive Weighting," J. Sarj. Tek. Inform., vol. 2, no. 2, pp. 1196-1205, 2014.

[13] A. A. Chamid and A. C. Murti, "Kombinasi Metode Ahp Dan Topsis Pada Sistem Pendukung Keputusan," Pros. SNATIF Ke-4, pp. 115-119, 2017.

[14] R. Kusumadewi, S. Hartati, A. Harjoko, and R. Wardoyo, Fuzzy Multi-Attribute Decision Making (Fuzzy MADM). Yogyakarta: Graha Ilmu, 2006.

TRANSFORMATIKA Vol. 17, No. 2, January 2020: $200-208$ 